\title{
The option of the replacement of post- traumatic defects and deformations bite facial wounds in children
}

\author{
Aleksey Chereda ${ }^{1}$
}

${ }^{1}$ Children's regional hospital, department of maxillofacial surgery and otorhinolaryngology, Petropavlovsk, Kazakhstan

CC.
BY $\begin{aligned} & \text { This work is licensed under a } \\ & \text { Creative Commons Attribution } 4.0 \\ & \text { International License }\end{aligned}$
J CLIN MED KAZ 2017; 3(45 SUPPL 3):67-69
Автор для корреспонденции: Череда Алексей
Витальевич, Детская областная больница, отделение
челюстно-лицевой хирургии и оториноларинголо-
гии. Адрес: 150007, ул. Пушкина 23, г. Петропав-
ловск, Казахстан. Телефон: раб. 8(7152)-46-99-24,
моб. +7(771)-107-16-51.
Е-mail: Hirurg1982hlx@mail.ru

\author{
БАЛАЛАРДАҒЫ ЖАРАЛАНҒАН ЖАРАҚАТТАРЫНАН КЕЙІНГІ \\ ТРАВМАТИКАЛЫК АҚАУЛАР МЕН ДЕФОРМАЦИЯЛАРДЫ \\ АУЫСТЫРУ МҮМКІНДІГІ \\ Череда А. В. ${ }^{1}$ \\ ${ }^{1}$ Балалар облыстық ауруханасы, жақсүйек-бет хирургиясы және оториноларингология бөлімі, \\ Петропавловск 23, Қазақстан.
}

\section{ВАРИАНТ ЗАМЕЩЕНИЯ ПОСТТРАВМАТИЧЕСКОГО ДЕФЕКТА И ДЕФОРМАЦИИ УКУШЕННЫХ РАН ЛИЦА У ДЕТЕЙ \\ Череда А.В. ${ }^{1}$ \\ ${ }^{1}$ Детская областная больница, отделение челюстно-лицевой хирургии и оториноларингологии, г. Петропавловск, Казахстан.}

\section{Введение}

За последние годы отмечается рост количества детей с укушенными ранами лица. Основной причиной роста укушенных ран является рост количества домашних животных. Родители, покупая щенка или котенка ребенку, часто забывают о том, что кошки и собаки -это хищники с присущими им инстинктами, за которыми надо ухаживать и иметь навыки общения с ними $[10,16]$. Среди животных, нанесших травму детям, преобладают домашние собаки $[4,5]$.

Отмечено, что дети имеют значительно больший риск травмы челюстно-лицевой области, чем взрослые, что приводит обширности повреждения мягких тканей лица и развитие рубцового процесса с деформацией лица порой требующих выполнения неоднократных реконструктивновосстановительных операций. [6,7].

Большинство травм челюстно-лицевой области у детей сопровождаются появлением посттравматических деформаций, обусловливающих задержку развития мягких тканей и роста лицевого скелета, нарушения косметических, функциональных особенностей и становится причиной инвалидности ребенка с последующей социальной изоляцией. [12, 13,15].

Более чем в половине наблюдениях выявляется обширные и глубокие пов-реждения с образованием истинного дефекта-части губы, щеки, носа и тд. [8].

Чаще всего замещение дефектов челюстно-лицевой области выполнятся пластикой местными тканями, пересадки свободых лоскутов, лосутов на ножке $[1,2,3]$.

\section{Клинический случай}

Пациент Г. 2007 г.р. поступил в отделение челюстнолицевой хирургии Детской областной больницы в июле 2009 года с диагнозом: Обширная укушенно-рваная рана в области щеки, верхней губы и угла рта справа. При поступлении отмечается обширная рана с дефектом и отсутствием тканей этой области. Рис.1.

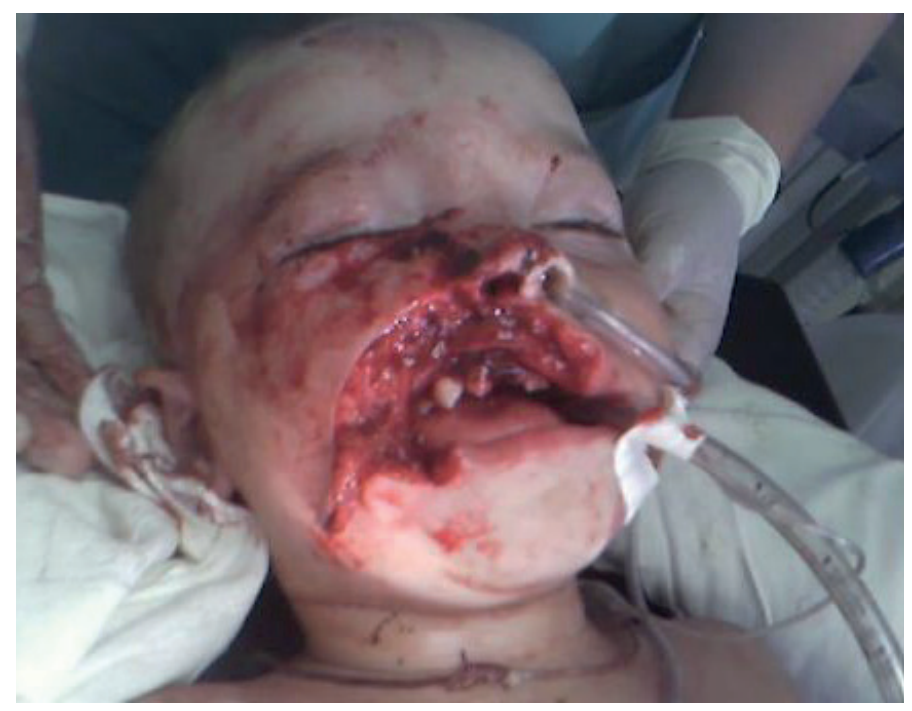

Рисунок 1

В течении первых часов выполнена ПХО раны, с частичным замещением дефекта отсутствующих тканей путем смещения левой половины губы и ротационными лоскутами со щеки. Рис. 2. 


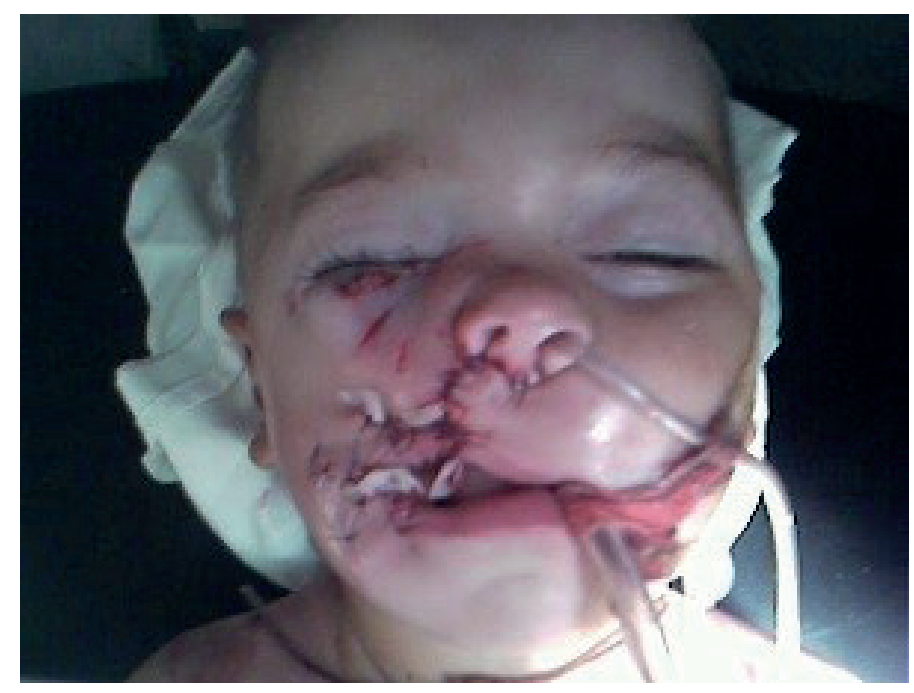

Рисунок 2

Через три месяца после травмы отмечается рубцовая деформация верхней губы, угла рта и щечной области справа. Рис.3.

Вторым этапом через 1,5 года после травмы в 2011 году выполнено иссечение рубцовой ткани щечной области

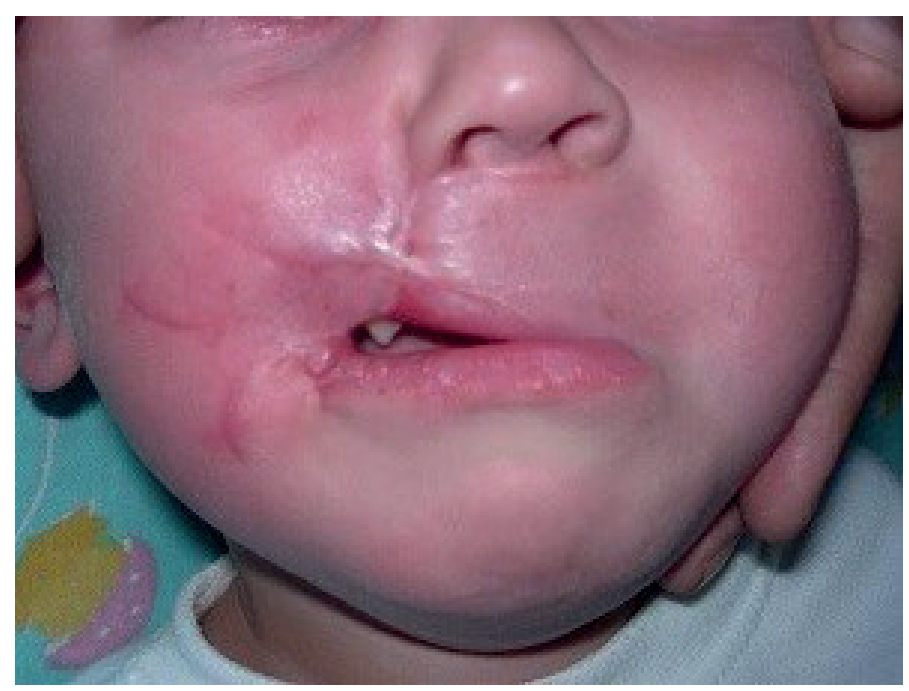

Рисунок 3

и верхней губы, угла рта справа, восстановление левой половины губы в правильное положение с одномоментным замещением дефекта ротационным кожным лоскутом с поднижнечелюстной области справа Рис. 4.5.6.7.

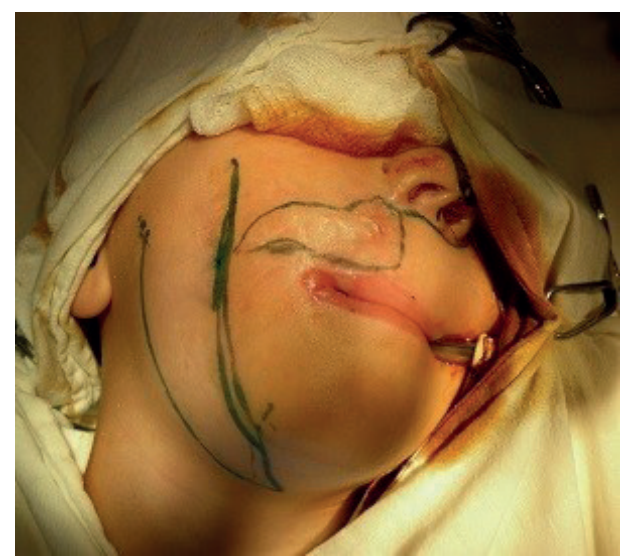

Рисунок 4

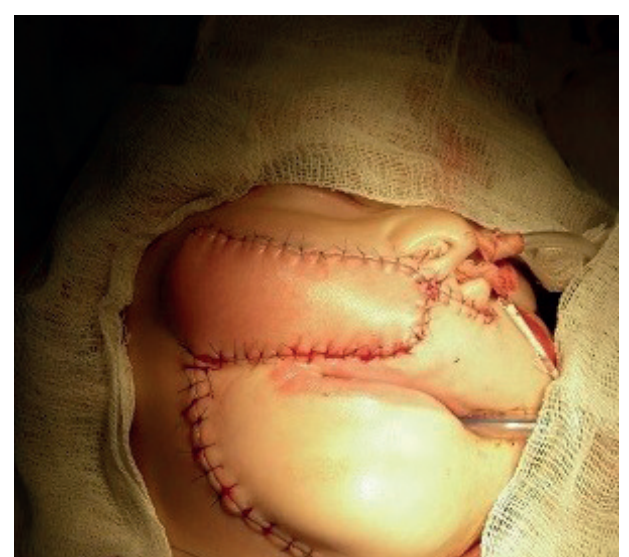

Рисунок 7

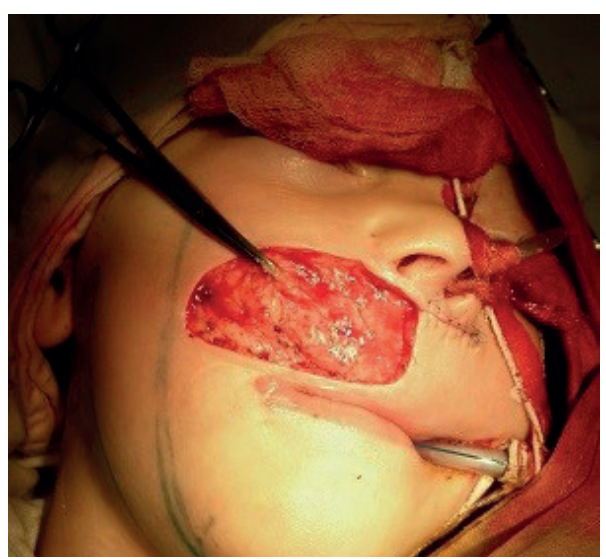

Рисунок 5

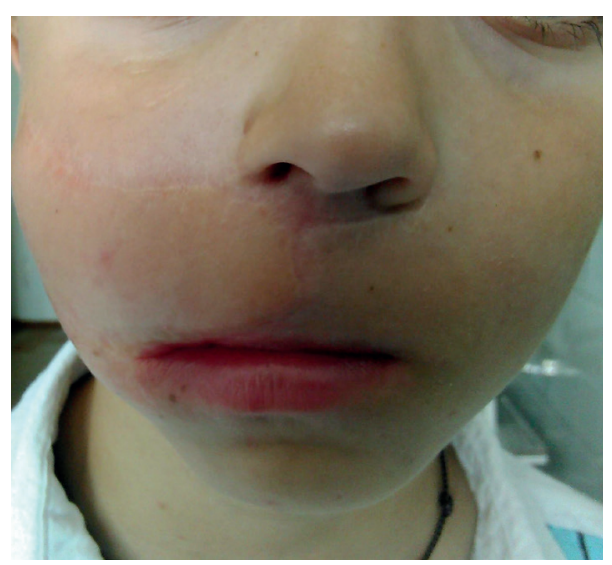

Рисунок 8

Через 12 мес в 2012 году третьем этапам проведено смещение ротационного слизистого лоскута со щеки на область угла рта и верхней губы.

На фоне рубцового процесса и роста ребенка, отмечалось уменьшение длины верхней губы с формированием микростомы за счет дефицита тканей, что потребовало дополнительной хирургической коррекций. Рис.8. В 2014 году выполнена операция пластика верхней губы путем перемещения на ножке треугольного лоскута Рис.10. дефекта. Рис.11.

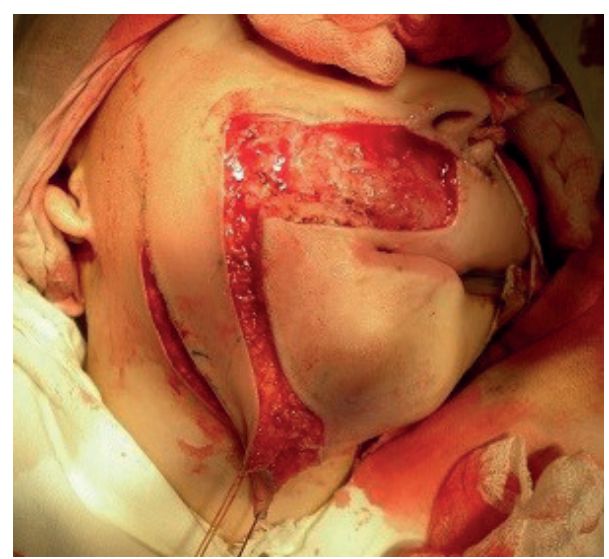

Рисунок 6

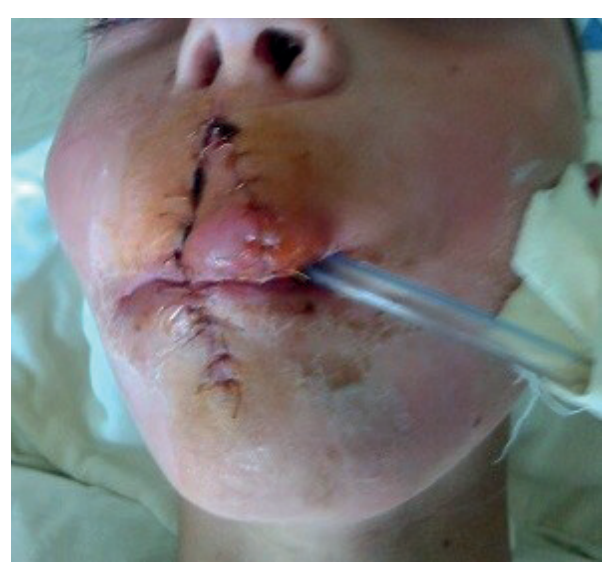

Рисунок 9

нижней губы (операция Аббе, 1898). Рис.9.

После проведенной операции отмечалось увеличение длины верхней губы и объема в центральном ее отделе.

В настоящий момент по данному случаю основной дефект щечной области, верхней губы и угла рта справа замещен. Отмечается незначительное опущение угла рта справа, что требует дальнейшей коррекции данного 

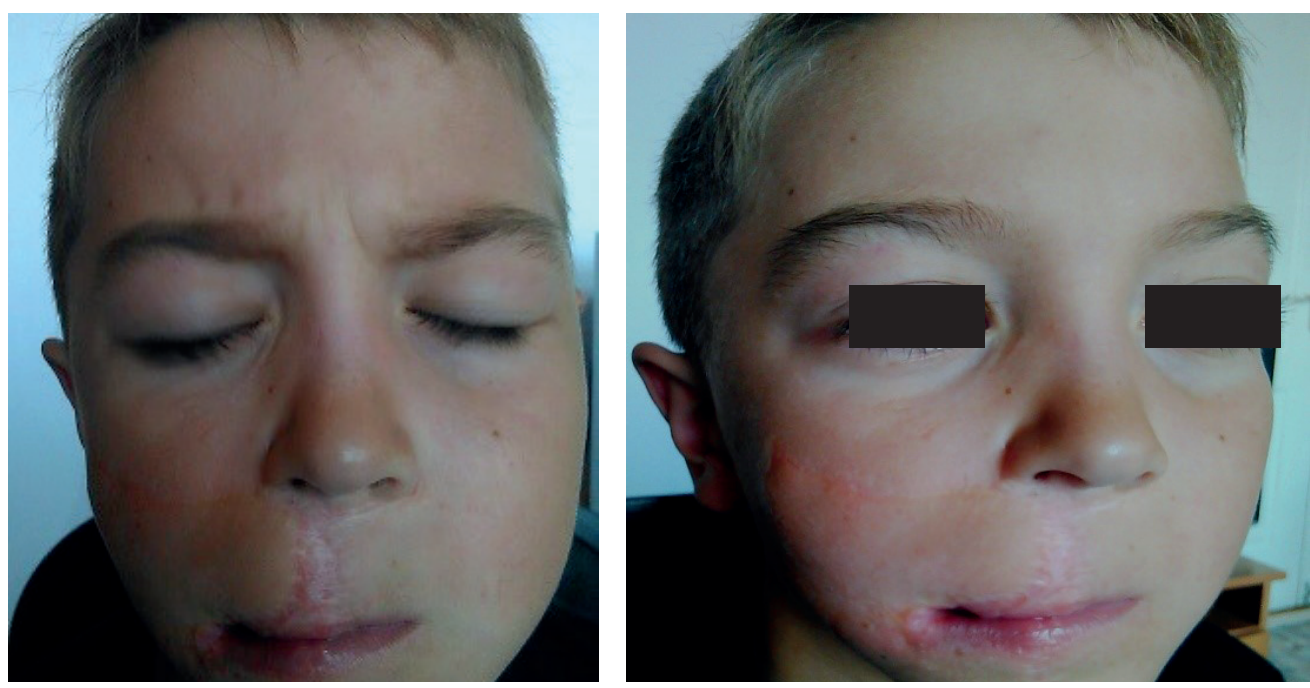

\section{Обсуждения}

Полученные

результаты в наблюдении за пациентом после каждой проведенной реконструктивновостановительной операции по замещению посттраматического дефекта лица и деформации отмечается улучшение эстетического и функционального состояния.

Таким образом, обширные укушенные раны челюстнолицевой области у детей заживали с формированием заметных деформирующих рубцов и дефектов на лице, для устранения которых требуется время. $[9,11,13]$

\section{Выводы}

В заключение анализируя данный случай можно сделать следующие выводы.

1. Укушенные раны с обширными дефектами челюстно-лицевой области не всегда могут быть закрыты одномоментно сразу после травмы и требуют многоэтапных реконструктивно-востановительных операций.

2. Этапные коррекции позволяют достичь хорошего анатомического и функционально результата.

3. Недостатки многоэтапных операций у детей это стрессовые состояния каждого последующего хирургического вмешательства у ребенка.

\section{Литература}

1. Aleksandrov N.M. Klinicheskaja operativnaja cheljustno-licevaja hirurgija (Clinical operative maxillofacial surgery) [in Russian]. 2th ed. Leningrad: Medicina; 1985. 54-110 p.

2. Balon L.R., Kostur B.K. Vozmeshhenie defektov cheljustno-licevoj oblasti i organov shei (Compensation for defects in the maxillofacial area and neck organs)[in Russian]. Leningrad: Medicina; 1989. 101-108 p.

3. Bernadskij Ju. I. Travmatologija i vosstanovitel'naja hirurgija cherepno- cheljustno-licevoj oblasti (Traumatology and reconstructive surgery of cranio-maxillofacial area) [in Russian]. 3th ed. Moskva: Meditsinskaya literatura; 1999. 224-225 p.

4. Zabelin A.S. Osobennosti lechenija bol'nyh s ukushennymi ranami lica i shei. (Features of treatment of patients with bitten wounds of the face and neck [in Russian]. Rossijskij stomatologicheskij zhurnal. 2005; 5: 40-4.

5. Korsak A. K., N. I. Petrovich, S. V. Lomako, T. A. Furs Original'nye nauchnye publikacii : Osobennosti kliniki i lechenija ukushennyh ran lica u detej (Original scientific publications: Features of the clinic and treatment of bitten wounds in children.) [in Russian]. 2012. 73 p.

6. Kurbanov UA. Pervichnaja rekonstrukcija ukushennyh defektov mjagkih tkanej. (Primary reconstruction of bitten soft tissue defects) [in Russian].

7. Limberg A.A. Planirovanie mestnoplasticheskih operacij na poverhnosti tela (Planning of local plastic operations on the surface of the body) [in Russian]. 166-167 p.

8. Rany mjagkih tkanej lica u detej. Struktura i osobennosti klinicheskih projavlenij (Wounds of soft tissues of the face in children. Structure and features of clinical manifestations) [in Russian]. Medicina i zdravoohranenie. 2016; 35.

9. Minhel'son N.M. Vosstanovitel'nye operacii cheljustno-licevoj oblasti (Restorative operations of the maxillofacial region) [in Russian]. 103-120.

10. Parshikova S. A., Parshikov V. V. Hirurgicheskoe lechenie ukushennyh ran lica u detej (Surgical treatment of bitten wounds of a person in children) [in Russian]. Med. al'manah. 2011; 19(6): 225-231.

11. Pshenichnova, E. S. Rezul'tat rekonstrukcii nosa posle ukusa sobaki. Annaly plasticheskoj, rekonstruktivnoj i jesteticheskoj hirurgii (The result of reconstruction of the nose after a dog bite. Annals of plastic, reconstructive and aesthetic surgery) [in Russian]. 2005; 3: 106-107.

12. Har'kov, L. V. Jakovenko L. N., Chehova I. L. Hirurgicheskaja stomatologija i cheljustno-licevaja hirurgija detskogo vozrasta (Surgical dentistry and maxillofacial surgery of childhood) [in Russian]. OOO Kniga pljus. 2005; 308-356.

13. A. V. Reznikova i dr. Hirurgicheskaja taktika lechenija i reabilitacii detej s ukushennymi ranami lica i shei (Surgical tactics of treatment and rehabilitation of children with bitten wounds of the face and neck) [in Russian]. 2002. 137-142.

14. Frantishek Burian. Atlas plasticheskoj hirurgii (Atlas of Plastic Surgery) [in Russian]. Tom 2, 1967. 195-259 p.

15. Mendez Gallart R., Gomez Tellado M. Dog bite-related injuries treated in a pediatric surgery department: analysis of 654 cases in 10 years. An Esp Pediatr. 2002; (56): 425-9.

16. Rusch M.D. Psychological adjustment in children after traumatic disfiguring injuries: a 12-month follow-up. Plast Reconstr Surg. 2000; 106 (7):1451-8. 